International Journal of Instruction e-ISSN: 1308-1470 • www.e-iji.net

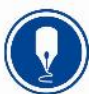

January $2019 \bullet$ Vol.12, No.1

p-ISSN: 1694-609X

pp. $1223-1238$

Received: 24/06/2018

Revision: 31/10/2018

Accepted: 06/11/2018

OnlineFirst: $15 / 12 / 2018$

\title{
Discourse Patterns in English as an L2 Classroom in India
}

\author{
Sarat Kumar Doley
}

Asst. Prof., Department of English and Foreign Languages, Tezpur University, India, dolesar@tzu.ernet.in

This paper is the outcome of a year-long case study exploring the pattern of discourse in undergraduate English as a second language (L2) classroom in Assam, India. Following the socio-culturally based theoretical perspective that language learning in an L2 classroom occurs within the context of guided discourse patterns, this study attempts at a description of the discourse patterns and strategies adopted by the L2 instructor in the classroom under scrutiny. In doing so, the study looks at the role of the instructor in the initiation and continuation of the spoken discourse between him and the L2 learners, mostly following the Initiation-ResponseFeedback (IRF) pattern, and among the L2 learners themselves. It also seeks to interpret the types and consequences of the style of questioning adopted by the instructor in terms of motivation for more oral exchanges among the L2 learners. The study shows that the high frequency of demonstrative questions from the instructor and IRF pattern of spoken discourse between the instructor and the L2 learners does not encourage the learners for longer oral interaction in the L2.

Keywords: second language acquisition, discourse analysis, English language teaching, bilingual learners, culture learning

\section{INTRODUCTION}

Discourse analysis has been described by SLA researchers and language educators (Hatch, 1978) as an approach to analyzing language development in real interactions that move beyond its purely structural functions. Representing the perspective of the majority of language teachers, McCarthy (1991) defines discourse analysis in this way: "Discourse analysis is concerned with the study of the relationship between language and the contexts in which it is used" (p. 5). This relationship between language and the contexts in which it is used is eloquently described by Wetherell et al. (2001):

Discourse analysis is probably best described as the study of talk and texts. It is a set of methods and theories for investigating language in use and language in social contexts. Discourse research offers routes into the study of meanings, a way of investigating the back-and-forth dialogues which constitute social action, along with the patterns of signification and representation which constitute culture. (p. i)

Citation: Doley, S. K. (2019). Discourse Patterns in English as an L2 Classroom in India. International Journal of Instruction, 12(1), 1223-1238. https://doi.org/10.29333/iji.2019.12178a 
So, discourse analysis is a multifaceted system and it investigates language use in its linguistic, social, cultural, and cognitive aspects. Because of the continuous pedagogical needs of language educators and increasingly diverse instructional inquiries of language teachers, classroom discourse analysis has been the focus of serious attention in second language acquisition (SLA) research. Classroom discourse analysis research in SLA attempts at a focus on ongoing oral interaction in the language classroom, the way speakers talk, and the purpose of their talks. A close investigation of the L2 classroom discourse, specifically the oral discourse between the L2 instructor and the learners in the classroom, along with the discourse among the L2 learners themselves, will enable the understanding of the learning process of the L2 learners as they co-construct cultural understanding with the L2 instructor, with each other, and with various types of texts in the classroom. Rightly pointing at this fact, Hellermann (2008) writes, “...the process of the co-construction of practices for talk in the classroom establishes a particular context for learning" (p. 67). Since English as a Second Language (ESL) classes attract learners from increasingly diverse backgrounds in India, it is crucial to explore this process of co-construction in the classroom.

So, the primary objective of this paper is to explore how English as a Second Language undergraduate class in India offers scope for oral interactions in the L2 between the L2 learners and the instructor as well as among the L2 learners themselves. The crucial moments in the classroom discourse are termed as moments of cultural discourse, and they are analyzed in detail. To be more precise, the moments of cultural discourse are understood as crucial moments when the oral classroom interactions and discussions focus on the joint construction of cultural understanding between the L2 instructor and L2 learners and among the L2 learners themselves. The large number of teacher controlled or instructor driven moments of cultural discourse observed in the study is the result of the Teacher Initiation-Learner Response-Teacher Feedback (IRF) pattern of oral interaction between the L2 instructor and the learners. The IRF pattern inhibits longer duration of discourse engagement on the part of the learners, significantly limiting the learners' opportunity for meaningful L2 use thereby. The instructor's question types tuned with the IRF pattern may further fail to encourage learners' elaborate L2 use.

\section{LITERATURE REVIEW}

There are a large number of SLA studies that attempted at an analysis of classroom discourse. Keeping in view the linguistic aspects of classroom interactions, the typical structure of classroom discourse is described by Sinclair and Coulthard (1975) and Mehan (1979) as IRF pattern which follows a sequence of well-ordered moves: I (teacher initiation) $\rightarrow \mathrm{R}$ (student response) $\rightarrow \mathrm{E} / \mathrm{F}$ (evaluation or feedback by teacher). Sinclair and Brazil (1982) and Cullen (2002) later renamed the feedback move as "follow up" to expand its scope to include its multiple functions and roles.

Swain and Lapkin $(1995,1998)$ coined the term language-related episode (LRE) taking into account the fact that language learners are proactive negotiators for meaningful communication both in and outside of the classroom. Language-related episode (LRE) was defined by Swain and Lapkin (1998, p. 326) as "any part of a dialogue in which 
language students talk about the language they are producing, question their language use, or correct themselves or others". Swain and Lapkin (1998) elaborated on the LREs in the context of a larger study on four grade 8 French immersion classes where the students carried out a jigsaw task. The students worked in pairs to construct a story based on a set of pictures and then wrote the story in collaboration using French to coconstruct the language they required to express the meaning. Considering the fact that the dialogue between the two students exhibited both the process of language learning and the communicative outcome, more frequent application of collaborative activities in second language learning were encouraged by Swain and Lapkin (1998).

By proposing discursive practice approach to consider the wide range of social variables of L2 learning, Young (2009) widened the boundary of classroom discourse analysis. Young's discursive practice views discourse as social action that is context grounded, emergent, negotiated, and situated. It understands and interprets verbal, nonverbal, and interactional activities in the contexts of their language- learning and language-using contexts of the L2 users following the current socio-cultural trend of L2 learning.

As far as the L2 learning in social framework is concerned, the discourse and interactional patterns during teacher-led whole class discussions in social studies classes that attempt to foster respect for cultural diversity and differences in mainstream high schools in Canada were examined by Duff (2002). He found the Chinese ESL students relatively quiet and passive in comparison with their classmates who were native speakers of English or had been in Canada for a long time, observing the turn-taking and other interaction patterns of the ESL students in a whole-class discussion on Chinese culture. Duff came to the conclusion by combining the analysis of different data sources that the interactional behaviours of the ESL students should be interpreted with reference to their prior educational socialization and cultural orientation.

The various ways in which language teachers in Chinese heritage language Schools in the US use teachers' directives in classroom discourse to convey Chinese cultural values were investigated by $\mathrm{He}$ (2000). He's study located the teacher's directives in the regular classroom as a speech event identified as instructional or initiating directives and disciplinary or responsive directives. In so doing, this study showed that the teachers were provided with the discourse tool to engage these young Chinese learners to coconstruct cultural knowledge by the grammatical and interactional organization of these classroom directives.

Donato and Brooks (2004) studied the classroom discourse in an advanced undergraduate Spanish literature course in an attempt to respond to the search for more empirical studies in content-based courses. Following the ACTFL Proficiency Guidelines, four features of the classroom transcripts were analyzed to see the ways in which discussion in advanced literature courses present discourse opportunities for learners to develop advanced language functions: discourse structure of the literary discussion, the use of teacher questions, verb tense distribution, and student uptake. The study showed that the learners were constrained from extended utterances by the dominance IRE pattern in the literary discussion and the learners' opportunities for discourse at the Advanced level on the ACTFL scale were further limited by the 
instructor's clear preference for display questions. Furthermore, it observed the dominant use of the present tense in discussion of literary topics and found that there was lack of student uptake of the corrective feedback of the instructor. Considering the importance of the connection between language and literature in pedagogical context, Donato and Brooks (2004) concludes by stating that there is a need for more investigation.

Despite the range of studies, discourse analysis is still rather a vague concept. SLA studies have incorporated discourse analysis approaching it either as a methodological framework or a theoretical construct. What these studies have done is that they have paved the way for further study on classroom discourse or "micro-interactional details" (He, 2003). In order to enact more macro-level socio-cultural construction, negotiation, and interpretation, we need a meticulous analysis of the classroom discourse that integrates the individual, social, and cultural aspects of language learning.

Although the management of the classroom is often within the capacity of the instructors more often than not in general, as the classroom discourse shows the presence of the authoritative voice of the language instructors (Hall, 2003), situations are not that distinctive in the case of culture learning in the classroom. There are frequent switches of authoritative voice between the language instructor and language learners. This is specifically so if the language instructor happens to be somebody who is not a native speaker of the language he or she is teaching. In this situation, what will be the approach of the language instructor? It will be of interest to see whether the instructor explains cultural information positioning himself as the expert or there will coconstruction of cultural knowledge. Shedding light on collaboration in pedagogical discourse, Donato $(2004$, p. 295) notes that " detailed analysis of the classes revealed that hen the teacher took the stance of non-knower and posed questions about students' cultural backgrounds for discussion, students participated actively and collaborated with each other".

Language learning is being viewed, as per Lantolf and Thorne (2006), as a process mediated partially through learner's developing use and control of language. According to this approach, individuals and their environment are mediated by language. This duality in the function of language in SLA is summarized by Kasper (2009) in this way, “...under an SCT perspective of L2 development, language serves the dual role of a mediating tool and goal of the learning process" (p. 273). Another core concept underlying much of socio-cultural SLA research is mediation which in the words of Lantolf (2011) focuses on "if and how learners develop the ability to use the new language to mediate (i.e., regulate or control) their mental and communicative activity" (p. 24). To be precise, learners use language as a mediational tool to establish connection between themselves and the social contexts in which the language is embedded in the language learning process.

So, it may be assumed that a closer look at the classroom discourse in language classroom may very effectively enable us to know about the ways in which discourse in language classroom provides scope for effective L2 learning and, more importantly, throws more light on the actual process of L2 learning in a classroom. It is more so in 
the context of the L2 research in Assam where there has been no research conducted till date on classroom discourse in relation to the teaching of English as an L2. The present study attempts to initiate such investigation by establishing the foundation for further research on this issue in the context of Assam, India.

\section{METHOD}

\section{The Research Site}

The research site is the first descriptive code of the situational context of the speech event first proposed by Hymes (1974) and later defined by Kramsch (1993). As far as the English language course investigated in this paper is concerned, it was advancedlevel English as an L2 course, known as the Alternative English course, at North Lakhimpur College, an Autonomous college affiliated to Dibrugarh University in the northern region of upper Assam of North East India. The Alternative English course-1, the first of the two-semester sequence that constitutes the first-year English course, was offered during the July-December Semester of 2014. It was an optional course for undergraduate learners who did not opt for the Modern Indian Languages course. It was supposed that learners who opted for this course should have at least received ten consecutive years of English language teaching in schools under Secondary Education Board of Assam, Assam Higher Secondary Education Council, Central Board of Secondary Education or other educational board offering similar learning experience.

Before enrolling in this course, all the L2 learners who participated in this case study, as described in a separate section of this paper, had their school education in schools within Assam, India. The class sessions were held three days a week on Tuesdays, Thursdays, and Saturdays regularly for 45 minutes except on holidays or for other unavoidable circumstances. Classes were held continuously for three months. All the recorded class sessions used in this paper were taken from classes held on Tuesdays.

\section{The Set-up of the Classroom}

For a comprehensive description and deeper understanding of the multifaceted nature of the context of classroom we need to consider the various factors associated with the language classroom. One of the most important of such factors is the physical set-up of the classroom. The first semester Alternative English classroom at North Lakhimpur College was in the old building of the college. It was bright and spacious ground-floor room with a seating capacity for around fifty learners. It is regretted that the room was not equipped with projector, computer, or a sound system. The researcher had to arrange for those instruments on the days of the class sessions. There were six rows of movable desks and benches in the room. Although the desks and benches were not arranged in semi- circle during other class sessions done in the room, the researcher arranged the desks and benches in semi-circle manner and the participant learners were seated that way in the front rows. The instructor stood in the middle of the classroom, near the table and whiteboard, and moved around as the discussion required him to.

At the request of the instructor, the researcher decided to place the voice recorder in the middle of the room. The researcher observed the class sessions in person. The instructor 
warned the researcher that the presence of a third party in the classroom might affect its naturalness. It is so accepted that this fact may be one of the major limitations of this case study. The researcher placed himself in a chair to the left of the instructor and to the right of the learners but in between the instructor and the learners so that the facial expressions and physical movements of the learner participants and the instructor can also be clearly observed. The voice recorder was placed between the learners and the instructor so that the voices of the instructor and the learners were recorded as clearly as possible.

\section{The Learner Participants}

The participants are the second descriptive code of the situational context of the speech events (Hymes, 1974). The participants are the people who take up the various roles of speakers and listeners in a particular speech event. Here in this study, the instructor and the learners enrolled in the first semester Alternative English course at North Lakhimpur College, as already mentioned elsewhere, were the learner participants.

During the study, the promise to preserve the real identities of the instructor and the learner participants was made and for that reason pseudonyms have been used throughout this paper. There were 30 students enrolled in the first semester Alternative English Course and 12 of them wanted to participate in the study. The researcher carried out a recruitment process with due permission from the Principal of North Lakhimpur College, the Head of the Department of English, and the instructor. An announcement about the study was made to the whole class at the beginning of the semester in the second week after the Summer Break. The non-participant learners, whose numbers varied on each of the class sessions, were allowed to sit in the class sessions but no information related to them were collected excluding the data from audio recorded classroom sessions. The classroom interaction data of the non-participant learners were the unavoidable product of the data collection procedure using the audio recorder in classroom observation for the reason that the study considered the whole class as a case and the objective of the analysis was the spoken discourse and interactions between the instructor and the learners in the classroom.

The profiles of the learner participants represented the common complexities of advanced-level English as an L2 course in Assam, India. The learner participants showed diverse profiles with reference to their academic background and English language learning experience. There were 5 male and 7 female learner participants and their ages ranged between 18 and 20. They were bona fide students of North Lakhimpur College pursuing different undergraduate courses at the college and all of them were freshmen at the time of the study. There were 6 learners majoring in English, 3 in Economics, 2 in Anthropology, and 1 in Education.

As far as the language backgrounds of the learner participants were concerned, 3 learners reported that they had been exposed to some amount of English even at home as their parents and guardians had some conversations in English with them at home regularly. They had the Indian variety of English in terms of pronunciation, vocabulary use, and sentence structure. Moreover, they reported that they watched Television 
programs and movies in English on a regular basis. All these learners were native speakers of Assamese, the official language of the state of Assam, India. The other nine learners were also native speakers of Assamese, with 3 learners identifying both Mising, a Tibeto-Burman language of a tribe in upper Assam, and Assamese as their native languages.

The English language experiences of the learner participants prior to their enrolment in the first semester Alternative English course at North Lakhimpur College showed some similarity. All the 12 learner participants had English language experiences ranging from 10 to 12 years at the time of filling out the demographic information form used in the study. None of the learner participants had the experience of study abroad. The only sources of English language learning other than their formal education in English were English newspapers, magazines, story books, English TV channels, English radio programs, English movies etc. Whatever cultural knowledge they had at the time of the study was through similar sources. The learner participants who gathered some English language experience through conversations in English every now and then with their parents and guardians had parents and guardians either with experiences of meeting native English speakers at some point of time in their life or they were highly educated. Besides, 7 of the 12 learner participants had studied 10 years of English at a local private English medium school at North Lakhimpur town and 2 years of English at North Lakhimpur College in the higher secondary section. The rest of the 5 learner participants came from other institutions located in places outside of North Lakhimpur town and had at least 10 years of English study experience before enrolment in the first semester Alternative English course at North Lakhimpur College. As already mentioned, the participants reported a number of ways to keep in touch with English language and culture such as reading story books, listening to music, watching TV programs, movies, and talking to friends or family members, apart from their classroom practices, home assignments, and preparations for quizzes and tests in English.

\section{The L2 Instructor}

The instructor of the first semester Alternative English course under study was a faculty member in the department of English of North Lakhimpur College. He had nine years of teaching English as an L2 at the tertiary level at the time of the study. He was the person responsible for syllabus design and the course management. The class sessions were shared among the three other faculty members in the department who co-taught the course under the guidance and with the approval of the Board of Studies. The concerned L2 instructor had been teaching the first semester Alternative English course for two academic sessions at the time of the study.

The instructor had an M.A. degree in English from Gauhati University, India, and he was not a native speaker of English. Before he started teaching English at the advancedlevel, he taught English at a higher secondary school where he gained the experience of teaching class $\mathrm{x}$, xi, and xii standard learners. The researcher discussed the study with him a couple of months before the start of the class sessions, and he was very keen on participating in the study. Along with the first semester Alternative English course, the 
instructor was teaching the major courses and the pass course in English at the time of the study.

\section{Methods of Data Collection}

There were various sources of data and the process of data collection from these sources involved several phases. The ethnographic information of the first semester Alternative English class was collected by the researcher, who took a non-participant observer position in the entire process, with the help of a demographic profile form. Besides the demographic information form, a host of class session recordings, pre- and post-course questionnaires, class discourse recollections with learner participants, an interview with the instructor, and the researcher's journals used for classroom observation are the tools through which data for the study were collected.

The recorded class sessions were the principal data source for the analysis of the classroom discourse under scrutiny for the reason that the focus of the study was on the spoken discourse and classroom interactions between the instructor and his learners in an advanced-level English as an L2 course. The Tuesday class sessions taught by the particular instructor, as mentioned elsewhere, throughout the 12-week semester were taken for observation. The total number of audio recorded class sessions used for analysis in the study was 9 . The other class observations of Thursday class sessions and the first two class sessions in Week 1 and 2 were not used for analysis.

The researcher was seated, as already mentioned, in the least interfering place between the learner participants and the instructor in the right hand corner of the classroom during the recorded class sessions. The researcher took the position of a non-participant observer and made no contribution whatsoever to the classroom activities and discussions. Although the researcher prepared field notes and an audio recorder was used to record the class session, video recordings of the class sessions would have been of immense help in reviewing the field notes taken during the sessions. The researcher could not carry out video recordings of the class sessions for the objections about the exposure of real identities raised by the instructor and the learner participants. The researcher still thinks that video recordings of the entire class sessions would have effectively facilitated the field note-taking by capturing the discourse strategies of the learner participants during the class sessions in real time.

\section{FINDINGS AND DISCUSSION}

\section{The IRF Pattern}

The regularly observed classroom discourse structure in the 9 audio recorded class sessions was the one initiated by the instructor, followed first by response from the learner, and then evaluation or feedback from the instructor. It was observed in these class sessions that the explanation of the topic by the instructor received an extended instructor-elaborated commentary as feedback in response to learner response. In the seventh recorded class session alone, 26 discourse sequences out of the 36 classroom discourse sequences followed this pattern. As shown in Example 1, the classroom spoken discourse followed the pattern of instructor initiation (I) seconded by learner 
response $(\mathrm{R})$ and instructor feedback $(\mathrm{F})$, and hereafter this pattern will be referred to as IRF (Sinclair \&Coulthard 1975;Mehan 1979).

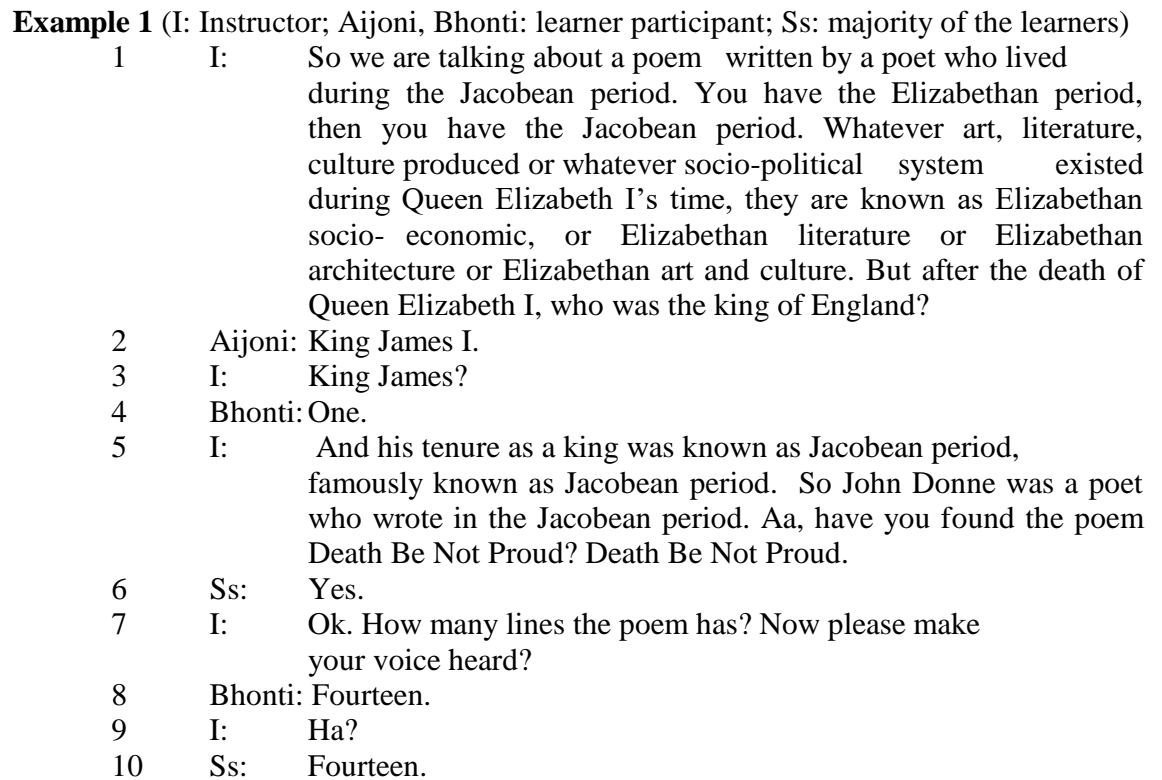

Example 1 shows that the instructor gave more detailed explanation in response to the learners' response to his initiation in the form of question to begin with. The instructor's extended elaboration exemplifies the third move of the IRF pattern of classroom discourse observed in the class session. The instructor's extended elaboration or feedback also serves as further initiating moves as new information are provided to the learners often in the form of questions to raise more curiosity about the topic. Since these questions are significant in the verbal interactions between the instructor and the learners in the classroom, an elaborate analysis of the instructor's style of questioning is offered in a separate section.

As far as the interactional arrangements in the class sessions are concerned, there were both a number of explicit rules for interaction and some implied routines of classroom discourse in the first semester Alternative English classroom at North Lakhimpur College. The first arrangement was that the instructor established the point of discourse in the classroom by an elaborate commentary in the form of introduction in the first part of the class sessions. If PowerPoint slides were shown, these slides reinforced the introductory commentary of the instructor. The second arrangement was that the instructor directed most of his questions to the whole class, and he called by the names of the learners to ask them to respond to his questions only in the cases of inadequate response and observed non-participation on the part of the learners. It was observed that his attempt was to engage the attention of the whole class and to make them participate in the discourse as much as possible. This attempt at establishing maximum learner 
participation in the classroom interactions was re-confirmed by the instructor in his interview with researcher. He further pointed out in the interview with the researcher later in the study that facilitating all the learners with an equal opportunity to participate in the classroom discussions also helped him create a democratic ambience in the classroom.

\section{Instructor's Question Types}

The analysis of the question types used by the instructor is based on an analysis of six class sessions during the semester. In these six class sessions there were 10 instances of elaborate discourse and the instructor raised 84 questions during these 10 instances. These questions were divided into four types- demonstrative questions, follow-up questions, clarification questions and imploring questions. These question types were clearly defined. Demonstrative questions were those questions of which the instructor knew the answer. Imploring questions were those in which the instructor requested the learners for unknown information. Explanatory questions were those in which the instructor asked the learners to provide more elaborate explanation of their responses. Follow-up questions were those questions asked by the instructor not in anticipation of any answer from the learners but as a link to more explanations from the instructor himself.

\section{Instructor's Style of Questioning}

The 10 instances of discourse used in the study showed that the number of demonstrative and follow-up questions raised by the instructor was larger than the number of clarifications and imploring questions raised during these instances. There were $28(33.33 \%)$ follow-up questions and 47 (55.95\%) demonstrative questions out of the total number of 84 questions asked by the instructor during those 10 instances.

The reasons for raising larger number of follow-up and demonstrative questions were the teaching goals that the instructor aimed at. The first goal was to check whether the learner had the necessary information related to culture mentioned in the text as a whole and the vocabulary in question in particular or not. The second goal was to direct the learners' attention to the culture related information that they might have failed to notice during the class sessions. An analysis of an excerpt from one of the instances of discourse during a recorded class session to illustrate the style of questioning adopted by the instructor is presented in Example 2 below.

Example 2 (I: Instructor; Pari: a learner particpant)

1 I: Right, for how many months a year it rains there? Sun comes out how often? Very, aa, for a very short time in Cherrapunji, right? And most of these places are very very wet, aren't they? They wear sweaters, these English men, most of the time in the year. Can you imagine a same kind of situation in England, cloud covers most of the year?

2 Pari: Cloudy.

Example 2 shows that the instructor asked five questions in total in search of response from the learners. The example presents a situation where the instructor attempted to 
engage the learners in a discussion around the topic of cold winter and rainy season in England and the dress habits of the British during those months. But the possibility of engaging the learners further in the discussion of the topic got affected by the final question of "Can you imagine a same kind of situation in England, cloud covers most of the year?" The final question had a statement providing cultural information preceding it and the question elicited only a one-word response from the learners. This question in Example 2 ended up with a convergent answer from the learners which stopped more elaborate discourse contributed by the learners on the topic brought up for discussion.

Moreover, another aspect of the style of questioning that the instructor adopted in the classroom discourse was the frequent use of tag questions by him. The instructor used tag questions like "Is that okay?", "Is that right?", "Okay?", "Right?", "Shall we?", "aren't they", " Is not it?" and so on. Since these tag questions were not used to elicit any response from the learners, the researcher has coded them as follow-up questions. There were $11(13 \%)$ tag questions out of the total number of 84 follow-up questions found in the 10 MCDs of the class sessions. These tag questions were frequently used by the instructor in the introduction of new information. In addition to this function of breaking in new information to the learners, these tag questions were also used as tonesoftener by the instructor in the course of his conversation and interaction with the learners during the class sessions.

\section{The Moments of Cultural Discourse (MCDs)}

Culture teaching in L2 classroom is understood in this study as a process of teaching in which teaching of cultural information provides instances for language use or the collaborative understanding of the cultural perspectives in the target culture facilitates scope for language learning in the classroom. Going by that definition of culture teaching in L2 classroom, moments of cultural discourse (MCDs)are the key moments of oral classroom interactions in the L2 between the instructor and the learners and among the learners themselves about the cultural practices or perspectives of the language community that speak the L2 in question as its mother tongue in which the cultural understanding is achieved in a collaborative discursive efforts put by the instructor and the learners and among the learners themselves in the classroom. There were $10 \mathrm{MCDs}$ coded jointly by the researcher and a second rater. The researcher and the second rater coded the MCDs individually and later the coded MCDs were checked for inter-rater reliability. The inter-rater reliability of the coded episodes was little over $92 \%$.

Depending upon the patterns of discourse in these $10 \mathrm{MCDs}$, they were grouped into three categories. The MCDs in which the cultural understanding was initiated by the instructor were in the first category. The MCDs in which the cultural understanding was initiated and achieved spontaneously by the collaborative negotiation of meaning by the learners themselves in the oral class discourse were in the second category. The third category of MCDs was the moments of cultural discourse in which the classroom interactions between the instructor and the learners and among the learners themselves stopped before the interactions achieved any cultural understanding. As far as the number of MCDs that falls into these three categories are concerned, majority of these episodes, 8 out of the 10 moments, belong to the first category. Only one moment of 
cultural discourse each falls to the remaining two categories. In the following section, an analysis of the first category of MCDs is presented.

\section{First Category of MCDs}

The structure of the classroom discourse was the conventional IRF pattern in which the instructor initiated the classroom discourse by making an introductory explanation of the cultural topics at the start of the class sessions followed first by responses from the learners and then by an extended commentary as feedback by the instructor. The instructor integrated the in-focus cultural topics in the poems selected as reading texts such as the "Christian concept of death", "mythological stories", "friendship" etc. with the vocabulary and sentence patterns used in the poems. The instructor's opening explanations of these English cultural perspectives were followed by the interactions between the instructor and the learners and among the learners. Since the instructor prepared the ground for discussion and debate by setting up the agenda for the classroom discourse on a particular topic in these 8 MCDs, these episodes in the first category were considered as episodes anchored by the instructor in this study. An analysis of an MCD of the first category is presented in Example 3.

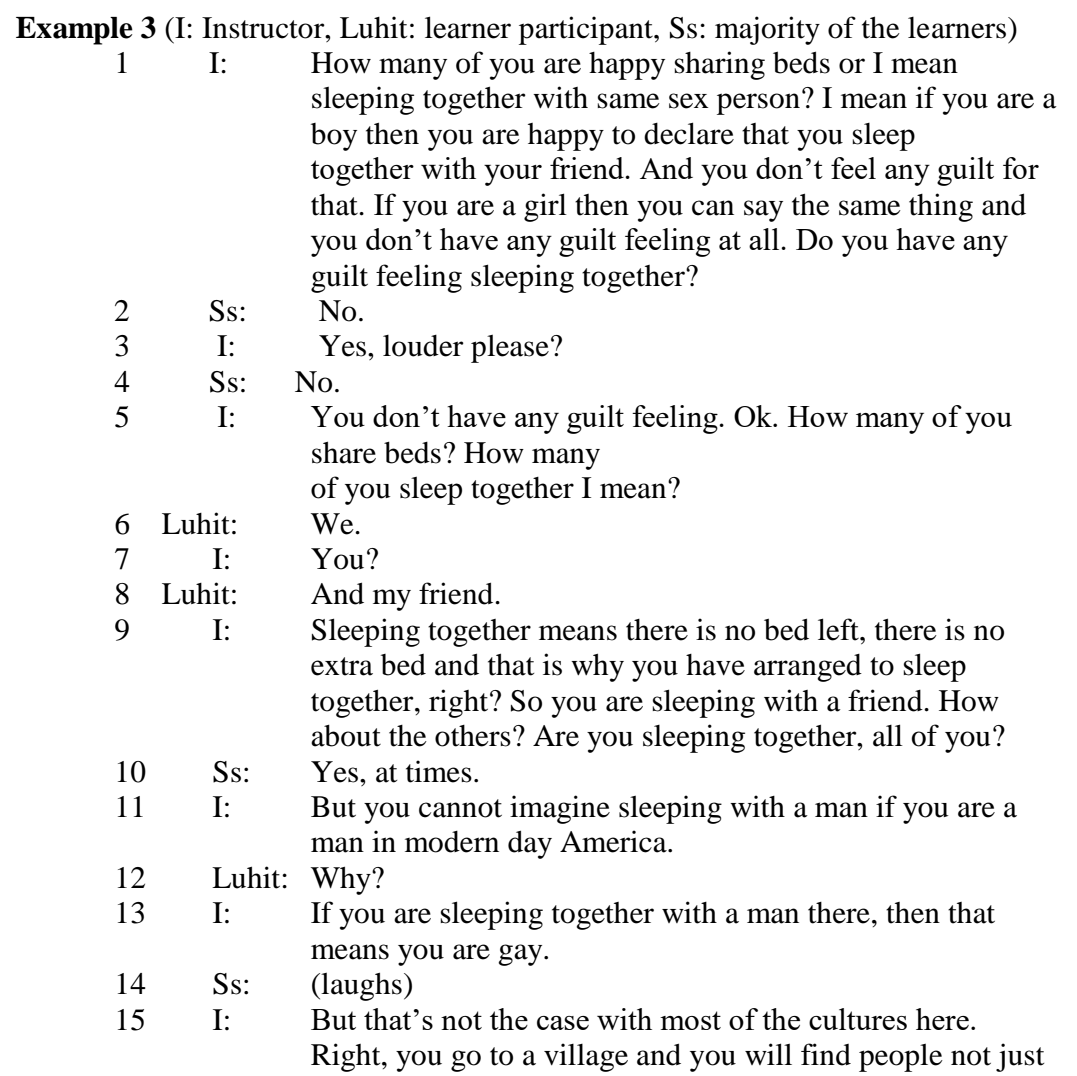




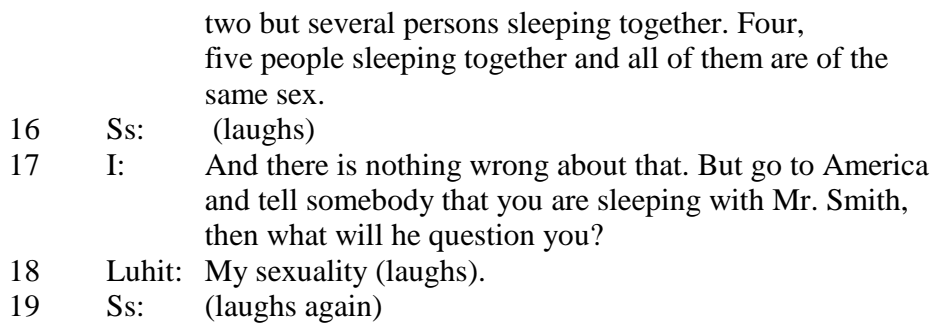

Example 3 is taken from MCD7 of Class Session 8. Here, the instructor is trying to make the learners understand the expression "sleep together". The class session was on same sex relationship with reference to the sonnets by William Shakespeare. The instructor was bringing in the issue of the perception of homosexuality in the west. The instructor was explaining that the perception associated with this sexual behaviour made the west take even an innocent act of sleeping together with a friend sexually seriously and analyze it as an instance of homosexuality. This outlook, the instructor was driving the point home by focusing on the expression "sleep together", was crucial in the understanding of the this phrase as an expression with sexual connotations. In turn 1 of Example 3, the instructor raises the issue of homosexuality by asking: "How many of you are happy sharing beds or I mean, sleeping together with same sex person?" But the instructor does not wait for the learner's response and provides a few more commentary on the issue followed by an imploring question: "Do you have any guilt feeling sleeping together?" By this question, which followed the explanation of the context in the two statements that preceded it, the instructor was trying to gather information about the learners' understanding of the cultural meaning of the expression besides its literal meaning. The learner responded by saying "no" and the instructor asked them to repeat their answer in a louder voice. The intention of the instructor was to keep the learners' literal understanding of the expression in the back of their mind to contrast it with the connotative meaning as he would explain the culture specific meaning of the expression in the later half the interaction.

In turn 5 of Example 3, the instructor asks two questions that look for the same answer: "How many of you share beds? How many of you sleep together I mean?" By asking these questions, the instructor followed the strategy of exploding the culture- specific meaning of the expression at the last moment to the learners in a dramatic manner. The question brought in response from only one learner participant, Luhit, in the classroom in the affirmative. The affirmative response from the learner participant further pointed to the fact that the learner participant did not know the culture specific connotative meaning of the expression. In turn 9 of Example 3, the instructor explained the literal meaning of the expression to confirm the learners' understanding of this meaning by saying, "Sleeping together means there is no bed left, there is no extra bed and that is why you have arranged to sleep together, right? So you are sleeping with a friend." $\mathrm{He}$ followed this explanation with an imploring question. The question was directed to the entire class: "How about the others? Are you sleeping together, all of you?" The learner participants answered in the affirmative this time leaving their hesitation, which may have been due to reluctance to participate in the $\mathrm{L} 2$, in the initial part of the interaction. 
As of now, the instructor was assured of their literal understanding of the expression "sleep together." In turn 11 of Example 3, the instructor provided cultural information by saying: "But you cannot imagine sleeping with a man if you are a man in modern day America." This was done by the instructor with the intention of creating surprise and curiosity among the learners. One of the learner participants, Luhit, asked "why?" Now the stage was set for declaration of the explosive culture-specific meaning of the expression. In turn 13 of Example 3, the instructor says, "If you are sleeping together with a man there, then that means you are gay." The learner participants understood the meaning and laughed at the misunderstanding. The instructor, in the rest of the class session as explanations of the expression, contrasted the cultural situation of the learner participants with the situation in the United States and elsewhere.

Despite the theatricality involved in the explanation and discussion of the expression "sleep together" in Example 3, the instructor was unable to elicit extended elaboration or commentary from the learner participants. The questioning style of the instructor in the use of a number of follow-up questions in a row prevented the learner participants from making elaborate statements in the interactions. The instructor's strategy of explaining and questioning ended up drawing only convergent utterances from the learner participants in Example 3. The cultural input was coming into the classroom discourse only through the instructor and the learner participants failed to show initiative in terms of elaborations and open ended discussions during the interactions

\section{CONCLUSION}

In the majority of the episodes of oral interaction or Moments of Cultural Discourse observed in the study, the L2 instructor attempted to provide the anchor for the initiation and completion of the cultural understanding of the L2 linguistic expressions. An oral interaction in the L2 in which the cultural understanding initiated and achieved spontaneously by the collaborative negotiation of meaning by the learners themselves in the oral class discourse could have created more elaborate L2 engagement in terms of more opportunities for L2 learners' language use. Looking at the advanced-level of the class under advisement, instead of the process of cultural understanding of the L2 linguistic expressions anchored and controlled by the cultural information and interpretation accorded singularly by the instructor by use of the IRF pattern, the process of cultural understanding may be allowed to be controlled more by the L2 learners themselves, with the L2 instructor playing as minimal role as possible. In line with the IRF discourse pattern adopted in the classroom, the instructor puts less emphasis on responses from the learner participants and focuses more on extended commentaries as elaboration on the topic and as a result this classroom discourse pattern precludes the creation of more moments of cultural discourse. More control on the part of the instructor in relation to the direction of the spoken classroom discourse in which the instructor had the opportunity of sticking to the topic in question instead of digressing into other topics because of learner intrusion and more freedom to the learners in relation to points of entry in the discussion in the cases in which the instructor shuts down the discussion by imposing the extended commentary immediately after a couple of responses from the learner participants would have led to more moments of cultural 
discourse. More moments of cultural discourse mean more opportunity of language use by the learner participants in the classroom.

Moreover, the high frequency of demonstrative and follow-up questions ended up eliciting only convergent responses from the learners in the form of short utterances. Moreover, the instructor used the method of asking multiple questions in a row in addition to the invocation of these two question types as part of his style of questioning. The learners on majority of the instances preferred to ignore the first few questions to await the final question that coincided with the pause on the part of the instructor.

The conclusion that is arrived at in relation to the questioning style of the instructor is that the questions raised by the instructor ended up almost on most occasions with oneword response from the learners. The major explanation for the style of questioning adopted by the instructor affecting the response from the learners is that the final demonstrative question following a number of follow-up questions asked by the instructor aimed only at particular factual information. It eventually closed off more elaborate discussion on the issue thereby. A more elaborate and comprehensive analysis of the specific reasons and fall out of the discourse patterns and styles of questioning adopted by L2 instructors elsewhere would be able to throw more light on this subject.

\section{REFERENCES}

Cole, K., \& Zuengler, J. (2008). The Research Process in Classroom Discourse Analysis: Current Perspective. Philadelphia : Lawrence Erlbaum Associates .

Cullen, R. (2002). Supportive Teacher Talk: The Importance of the F-move .ELT Journal , 56(2), 117-127.

Donato, R. (2004). Aspects of Collaboration in Pedagogical Discourse . Annual Review of Applied Linguistics , 24, 284-302.

Donato, R., \& Brooks, F. (2004). Literary Discussions and Advanced Speaking Functions: Research the Dis(connection). Foreign Language Annals , 37, 183-199.

Duff, P. A. (2002). The Discursive Co-construction of Knowledge, Identity, and Difference: An Ethnography of Communication in the High School Mainstream . Applied Linguistics , 23, 289-322.

Hall, J. K. (2004). "Practicing Speaking" in Spanish: Lessons from a High School Foreign Language Classroom. In D. Boxer, \& A. Cohen (Eds.), Studying Speaking to Inform Second Language Learning (pp. 68-87). Clevedon, England : Multilingual Matters.

Hatch, E. (1978). Second Language Acquisition: A Book of Readings . Newbury House: Rowley, MA.

He, A. (2000). The Grammatical and Interactional Organisation of Teachers' Directives: Implication for Socializations of Chinese American Children. Linguistics \& Education , $11,119-140$. 
He, A. (2003). Novices and Their Speech Roles in Chinese Heritage Language Classes. In R. Bayley, \& S. R. Schecter (Eds.), Language Socialization in Bilingual and Multilingual Societies (pp. 128-146). Clevedon: Multilingual Matters.

Hellermann, J. (2008). The Contextualization of Participation in the Asthma Project: Response Sequences in Classroom Talk. In K. M. Cole, \& J. Zuengler(Eds.), The Research Process in Classroom Discourse Analysis: Current Perspectives (pp. 49-72). New York: Lawrence Erlbaum Associates.

Hymes, D. (1974). Foundations in Socio-linguistics. Philadelphia: University of Pennysylvania Press.

Kasper, G. (2009). L2 Pragmatic Development. In W. C. Ritchie, \& T. K. Bhatia (Eds.), The New Handbook of Second Language Acquisition (2nd ed.) (pp. 259-284). Bingley, UK: Emerald.

Kramsch, C. (1993). Context and Culture in Language Teaching. Oxford: Oxford University Press.

Lantolf, J. (2011). The sociocultural approach to second language acquisition: Sociocultural theory, second language acquisition, and artificial L2 development. In D. Atkinson (Ed.), Alternative approaches to second language acquisition (pp. 24-47). New York: Routledge.

Lantolf, J., \& Thorne, S. (2006). Sociocultural Theory and the Genesis of Second Language Development. Rowley, MA: Newbury House Publishers.

McCarthy, M. (1991). Discourse Analysis for Language Teachers. New York: Cambridge University Press.

Mehan, H. (1979). Learning Lessons: Social Organization in the Classroom.Cambridge: Harvard University Press.

Wetherell, M., Taylor, S., \& Yates, S. J. (2001). Discourse as Data: A Guide for Analysis. Thousand Oaks, CA: Sage.

Sinclair, J. M., \& Coulthard, R. M. (1975). Towards an Analysis of Discourse: The English Used by Teachers and Pupils. London: Oxford University Press.

Sinclair, J. M., \& Brazil, D. (1982). Teacher talk. Oxford: Oxford University Press.

Swain, M., \& Lapkin, S. (1998). Interaction and Second language Learning: Two Adolescent French Immersion Students Working Together. Modern Language Journal , $82,320-337$.

Swain, M., \& Lapkin, S. (1995). Problems in Output and the Cognitive Processes They Generate: A Step towards Second language Learning. Applied Linguistics, 16, 371-391.

Young, R. (2009). Discursive Practice in Language Learning and Teaching. Malden, MA: Wiley-Blackwell. 